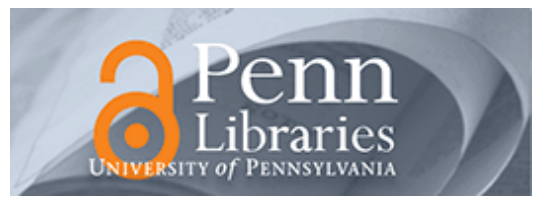

University of Pennsylvania

ScholarlyCommons

Management Papers

Wharton Faculty Research

8-2009

\title{
On Good Scholarship, Goal Setting, and Scholars Gone Wild
}

Lisa D. Ordóñez

Maurice E. Schweitzer

University of Pennsylvania

Adam D. Galinsky

Max H. Bazerman

Follow this and additional works at: https://repository.upenn.edu/mgmt_papers

Part of the Business Administration, Management, and Operations Commons, Business and Corporate Communications Commons, Business Intelligence Commons, Educational Administration and Supervision Commons, Educational Assessment, Evaluation, and Research Commons, and the Management Sciences and Quantitative Methods Commons

\section{Recommended Citation}

Ordóñez, L. D., Schweitzer, M. E., Galinsky, A. D., \& Bazerman, M. H. (2009). On Good Scholarship, Goal Setting, and Scholars Gone Wild. Academy of Management Perspectives, 23 (3), 82-87. http://dx.doi.org/ 10.5465/AMP.2009.43479265

This paper is posted at ScholarlyCommons. https://repository.upenn.edu/mgmt_papers/318

For more information, please contact repository@pobox.upenn.edu. 


\title{
On Good Scholarship, Goal Setting, and Scholars Gone Wild
}

\author{
Abstract \\ In this article, we define good scholarship, highlight our points of disagreement with Locke and Latham \\ (2009), and call for further academic research to examine the full range of goal setting's effects. We \\ reiterate our original claim that goal setting, like a potent medication, can produce both beneficial effects \\ and systematic, negative outcomes (Ordóñez, Schweitzer, Galinsky,\& Bazerman, 2009), and as a result, it \\ should be carefully prescribed and closely monitored.

\section{Keywords} \\ learning and scholarship, education research, education aims and objectives, goal setting in personnel \\ management, program effectiveness, effective teaching

\section{Disciplines} \\ Business Administration, Management, and Operations | Business and Corporate Communications | \\ Business Intelligence | Educational Administration and Supervision | Educational Assessment, Evaluation, \\ and Research | Management Sciences and Quantitative Methods
}


On Good Scholarship, Goal Setting, and Scholars Gone Wild

by Lisa D. Ordóñez, Maurice E. Schweitzer, Adam D. Galinsky, and Max H. Bazerman

Lisa D. Ordóñez (lordonez@u.arizona.edu) is a Professor at Eller College of Management, University of Arizona.

*Maurice E. Schweitzer (schweitz@wharton.upenn.edu) is an Associate Professor at The Wharton School, University of Pennsylvania.

Adam D. Galinsky (agalinsky@kellogg.northwestern.edu) is the Kaplan Professor at Kellogg School of Management, Northwestern University.

Max H. Bazerman (mbazerman@hbs.edu) is the Straus Professor at Harvard Business School, Harvard University.

*Contact author. 


\section{Executive Summary}

In this article, we define good scholarship, highlight our points of disagreement with Locke and Latham (2009), and call for further academic research to examine the full range of goal setting's effects. We reiterate our original claim that goal setting, like a potent medication, can produce both beneficial effects and systematic, negative outcomes (Ordóñez, Schweitzer, Galinsky, \& Bazerman, 2009), and as a result, it should be carefully prescribed and closely monitored. 
In 1999, the FDA approved Merck's arthritis drug Vioxx. Through clinical drug trials, Vioxx had been subjected to rigorous tests and careful research. Soon after approval, however, Merck began to receive anecdotal evidence about patients who suffered heart attacks while taking the drug. Of course, many people suffer from cardiovascular disease and heart attacks are multiply determined. How then, should executives at Merck respond? Since Vioxx had already been subjected to rigorous testing, should the "anecdotal evidence” be dismissed? Or, should Merck conduct additional research exploring the possible link between Vioxx and heart disease? And, even before there is definitive proof linking Vioxx and heart disease, is it reasonable for doctors to become more wary of prescribing the drug?

Locke and Latham (2009) deem anecdotes unworthy of academic attention. Further, Locke and Latham (2009) argue that as long as the benefits of a strategy are causally determined, while the negative effects have been shown in only a few causal studies along with many anecdotal accounts, we should dismiss the negative findings.

We profoundly disagree. We think that qualitative analyses, case studies, journalistic accounts, and anecdotes should all be used to raise questions, focus attention, and develop ideas that should be subjected to rigorous, causal analyses.

We believe that our disagreements with Locke and Latham highlight not only our differences about goal setting, but also about what constitutes good scholarship. In this response to Locke and Latham (2009), we articulate the aims of our first article (Ordóñez, Schweitzer, Galinsky, \& Bazerman, 2009), describe points of disagreement with Locke and Latham (2009), offer a definition of good scholarship, and suggest a program of research for future goal setting studies.

\section{Our Objectives}

We wrote our initial article (Ordóñez et al., 2009) within the context of the existing goal setting literature and the ubiquitous use of goals in managerial practice. We did not aspire to review - yet again — the goal setting literature. Instead, our aim was to raise questions, suggest

caution, and issue a call for future research. To convey our message, we invoke a metaphor: goal setting as a prescription strength medication that has both powerful positive effects and formidable negative side-effects.

Although most goal setting studies have documented beneficial effects, we believe that anecdotes and empirical results linking goals with harmful outcomes deserve much more attention and more systematic research. Given that one large negative effect can overwhelm the influence of many positive effects, our aim was simply to state that the possibility of systematic harm resulting from goal setting merits far greater academic scrutiny and managerial attention.

\section{Points of Disagreement with Locke and Latham (2009)}


Anecdotal evidence. Locke and Latham (2009) dismiss our concerns about goal setting by conveying the impression that the foundation for our thesis rests almost entirely on a few anecdotes. Locke and Latham (2009) seek to persuade the reader on this point through shear repetition: "largely anecdotes," "treating anecdotes as evidence," "reporting selected 'war stories'." Locke and Latham (2009) claim that we believe "research is to be ignored and news reports are to be embraced," and that "it is incomprehensible that scholars, rather than subject their speculation to programmatic research, would simply rely on stories in news periodicals."

In response, we offer three replies. First, Locke and Latham's (2009) characterization of our view of scholarship: "research is to be ignored and news reports are to be embraced," is simply wrong. There is mounting causal evidence linking goal setting with a range of behaviors including a shift in risk taking (Larrick, Heath, \& Wu, in press), greater unethical behavior (Schweitzer, Ordóñez, \& Douma, 2004), and a narrow focus that draws attention from other important elements of the problem (Staw \& Boettger, 1990). Ordóñez et al. (2009) cite these and other empirically-based articles that demonstrate a causal link between goal setting and harmful behavior.

Second, we continue to believe that anecdotes, case studies, and journalistic accounts can inform important research questions. Do anecdotes prove causality? Of course not. Can anecdotes help spotlight issues that merit caution and further investigation? Absolutely. Both in our initial article and here we explicitly call for further research.

Third, what should we do as the anecdotal evidence continues to mount? For example, consider General Motors' use of goal setting in 2002. At that time, GM had 28.2\% of the car and light truck market in the United States. GM executives set a specific, stretch goal of capturing $29 \%$ of the market. To gain commitment to this goal, G.M. executives wore pins with the numeral "29" (Maynard, 2002). In an effort to reach this goal, GM expanded its offering of interest free loans and "no money down" incentives. As GM lost money on a per unit basis, few executives stopped to focus on the implications of this narrow goal. "Fixated on this target, the firm went on to make decision after disastrous decision that helped drag it to the brink of bankruptcy” (“The perils of goal-setting," 2009). GM may never achieve their goal of 29\% market share, but in pursuit of this specific, stretch goal, GM executives damaged the profitability of a once great company.

Or, consider HUD’s low-income lending goals for Fannie Mae and Freddie Mac. These specific, stretch goals significantly expanded in 2001-2003 (e.g., a goal of at least 20 percent of mortgage purchases dedicated for low- or very low-income families in low-income areas, compared to a corresponding goal of 14 percent in 1997-2000), pushing Fannie Mae and Freddie Mac to make many risky and unprofitable loans. Since the collapse of Fannie Mae and Freddie Mac in 2008, it is clear that these stretch goals at Fannie and Freddie have had huge implications for American tax payers. 
Are these stories of GM and Fannie Mae and Freddie Mac anecdotes? Yes. Should these accounts cause us to think more carefully about how we set and use goals? Yes. And, do we still need more research on goal setting? Absolutely!

Minimizing the problem. In reference to Schweitzer et al. (2004) documenting a causal relationship between goals setting and cheating, Locke and Latham (2009) respond "fair enough, but is this a typical finding?” It is not a typical finding, but this is our point. If further work examined goal setting under conditions that permitted cheating, we postulate that findings linking goals with cheating might be far more typical than Locke and Latham suppose. Ultimately, this is an empirical question, and we call on scholars studying goal setting to design studies that allow for and measure a wide range of goal setting effects (including intrinsic motivation, cheating, and risk tolerance).

New evidence. Locke and Latham (2009) criticize our Academy of Management Perspectives article for not reporting results from new studies. Though it should be apparent to any reader of the Academy of Management Perspectives, our aim was not to report new studies. Consistent with the journal's objectives (from the AMP website), we aimed to "make information about empirical research in management accessible to the non-expert.” Suggesting that our article somehow fell short for failing to report new data misrepresents the mission of the journal.

Originality. After thoroughly criticizing our conclusions, Locke and Latham then support the very claims we propose by stating that they "were among the first to alert practitioners to the possible dangers of setting goals.” We agree and cited them in our original paper. However, their prior work falls short. They offer an incomplete account of the hazards of setting goals and convey the impression that these problems are minor, and unworthy of significant concern and future research.

In contrast, we postulate that goal setting may cause deep, systematic problems far more serious than prior work suggests. We postulate that the mild "solutions" Locke and Latham propose, most of them untested, may fail to solve these problems. In addition, the goal setting "pitfalls" Locke and Latham identify have generated surprisingly little research attention from leading goal setting scholars. Thus, we continue to call for more research that allows equal measurement of the potential negative side effects.

Out of context. When should goals be used? After accusing us of selectively citing sources, Locke and Latham (2009) quote us out of context. They suggest that we propose that "goals should be used only in the narrowest of circumstances." Though this might possibly be true, what we actually stated was the following:

In particular, we encourage managers to ask themselves the questions listed in Table 1 when considering the use of goals. This cautious approach to setting 
goals is consistent with King and Burton's (2003) claim that goals should be used only in the narrowest of circumstances.

Until further research is conducted, we are not able to articulate when goal setting should be implemented, when it should be abandoned, and under which conditions goal setting can achieve its aims with as few side-effects as possible.

\section{Good Scholarship}

Defining Scholarship. Although good scholarship can take many forms, a necessary condition for good scholarship is asking interesting questions which address important issues and/or challenge existing beliefs.

A second component of good scholarship is generating new knowledge. New knowledge changes the way individuals think about a problem or solve a vexing conundrum. New knowledge often emerges not from an individual study but across studies, across researchers, and across methodologies. Sometimes it emerges through theoretical analysis and other times through empirical research. There are many approaches to generating new knowledge, and different approaches offer trade-offs. For example, laboratory research may establish internal validity at the expense of external validity.

A third component of good scholarship, especially in the social sciences, is sound empirics. Whether scholars measure or manipulate constructs, it is important that these constructs accurately reflect underlying conceptual variables. Careful scholarship establishes causal relationships by disentangling confounds, ruling-out competing explanations, and maintaining internal consistency.

A fourth component of good scholarship is generating implications. Good scholarship has implications for theory, practice, or both.

Finally, good scholarship is broadly disseminated and widely consumed. Most typically, scholars convey new ideas through effective writing and speaking in prominent forums and outlets.

Producing Good Scholarship. Good scholarship is the product of healthy academic environments, ones in which curious scholars with open minds and different perspectives are encouraged to vet ideas. Ultimately, this vetting process will produce new knowledge.

Within our institutions, we have an obligation to create communities committed to openminded debate. In many cases, good scholarship will require academics to raise difficult questions about favored theories. When this happens, it is important to avoid ad hominem attacks. More specifically, senior colleagues should not only advocate for the use of “dispassionate language”( Locke \& Latham, 2009), but actually use this language themselves. This would require scholars to curtail their use of disparaging accusations such as "egregious 
scholarship,” "poor scholarship”, “irresponsible”, "unscholarly attacks”, and sentences such as, "Ordóñez et al. (2009) would do well to abandon their roles as reporters with an axe to grind and embrace good scholarship.”

When Locke and Latham accuse scholars who raise legitimate concerns about their favorite theory of having "breached the principles of good scholarship" they cause harm to the “dispassionate” approach to research they purportedly endorse and to good scholarship more generally.

\section{Future Research Directions}

We see our lively debate in the Academy of Management Perspectives as an open call for a more systematic investigation of the negative effects of goals that can lead to systematic problems in organizations. Thus, we reiterate our call for a program of research to investigate how "goals go wild." We hope that this program of research will be conducted by independent researchers from many institutions on many continents. This research should take multiple forms, both in and outside the lab, and should cover a range of potential outcomes.

Three areas with significant prospects for illuminating potential problems are the links between goal setting and unethical behavior, goal setting and excessive risk-taking, and goal setting and judgment. As financial crises, Ponzi schemes, and the collapse of the automotive industry demonstrate, the combination of unethical behavior, risk-taking and poor judgment can be toxic. We are not implying that goal setting was the primary cause of the current crises. Instead, we suggest that we should develop and sharpen our understanding of those contextual factors that produce harmful behaviors. We believe that goal setting research can develop our understanding of how some harmful behaviors systematically occur.

Although empirical evidence has started to accumulate linking goals with negative outcomes, we now need to develop theoretical frameworks that can simultaneously explain both the positive and the negative outcomes of goals. One good example of this type of research is the theoretical framework developed by Barsky (2008). This framework details the cognitive and motivational mechanisms of goal setting. Drawing on previous research (Schweitzer et al., 2004), Barsky (2008) develops a theoretical foundation in which goals hinder ethical recognition and promote moral disengagement, leading to unethical behavior.

In addition, Heath, Larrick, and Wu (1999) developed a model of goal setting which equates goals with reference points, evoking Prospect Theory as a foundation (Kahneman \& Tversky, 1979). This "goals as reference points” model explains previous goal setting results while also predicting new findings such as goal-induced risk taking (Larrick et al., in press).

Many other questions remain to be addressed. For example, how are goals set in competitive environments? Do executives in organizations in extremely competitive environments set different goals than do executives in less competitive environments? How do 
individuals in organizations manipulate the process of setting goals for their own personal benefit? Under what conditions are individuals likely to set the wrong type of goals (e.g., quantity rather than quality, revenue rather than profit)?

One particularly pressing issue is the interplay between culture and goal setting. We think there may be a reciprocal interplay between goal setting and organizational context. Not only is organizational culture likely to influence goal setting (as Locke \& Latham, 2009 suggest), but the use of goal setting is also likely to influence organizational culture. For example, when executives employ "management by objectives" they communicate an important message about the relative importance they place on process and outcomes.

There is fertile ground to continue investigating the boundary conditions of goal setting, especially situations in which goals are applied in the larger context of an organization. As both Locke and Latham (2009) and we point out, focusing on specific goals narrows our focus and can lead to unintended but predictable consequences. Further research in this area may help us determine warning signals or pinpoint the problematic conditions under which goals focus our attention too narrowly, with too much risk and without ethical constraints.

Although all four of us are primarily laboratory experimentalists, we believe that the method must match the research problem, and that we should always be aware of the limits and biases of our methods. The laboratory allows us to identify new effects and to prove their causal pattern. But, laboratories are weak instruments for measuring the strengths of effects in real contexts, especially when the context itself (e.g., organizational culture) is of interest, since experimentalists have so much control over the strengths of the manipulations.

Good scholarship requires that we see the barriers to discovery created by our preferred methods. In the common structure of laboratory goal setting research, the possibility of ignoring non-measured outcomes, taking unhealthy risks, and engaging in unethical behavior have typically been eliminated as concerns by the nature of the experimental task.

Ordóñez et al. (2009) call for future research to investigate both the constructive and the harmful effects of goals. This will require new and creative approaches, so that variables not explored in the mainstream goal setting area can emerge and be better understood.

\section{Conclusion}

Soon after Merck launched Vioxx, it became a commercial success. Though a few stories, and some experimental evidence, linked Vioxx with heart attacks, executives at Merck dismissed these "anecdotes" and continued to promote Vioxx. Over the next five years, pharmacists in the U.S. would fill over 80 million Vioxx prescriptions. It was only in 2004, after the evidence became incontrovertible that Merck withdrew Vioxx from the market. 
Goal setting, of course, is not Vioxx. As scholars, however, we can use this analogy to appreciate the dilemma that Merck's executives faced. When confronted by anecdotal evidence and some causal evidence, how should one react?

Setting a model for the dispassionate dialogue Locke and Latham (2009) purport to support, they ask "Falsehoods and insults aside, are Ordóñez et al. (2009) implying that more knowledge about goals is yet to be discovered?” You bet we do! 


\section{References}

Barsky, A. (2008). Understanding the ethical cost of organizational goal-setting: A review and theory development. Journal of Business Ethics, 81(1), 63-81.

Heath, C., Larrick, R. P., \& Wu, G. (1999). Goals as Reference Points. Cognitive Psychology, 38(1), 79-109.

Kahneman, D., \& Tversky, A. (1979). Prospect Theory: An Analysis of Decision under Risk. Econometrica, 47(2), 263-91.

King, L. A., \& Burton, C. M. (2003). The hazards of goal pursuit. In E. Chang \& L. Sanna (Eds). Virtue, vice, and personality: The complexity of behavior (pp. 53-69). Washington, DC: American Psychological Association.

Larrick, R. P., Heath, C., \& Wu, G. (1900). Goal-Induced Risk Taking in Negotiation and Decision Making. Social Cognition.

Locke, E. A., \& Latham, G. P. (2009). Has Goal Setting Gone Wild, or Have Its Attackers Abandoned Good Scholarship? Academy of Management Perspectives, 23(1), 17-23.

Locke, E. A., Latham, G. P., Smith, K. J., \& Wood, R. E. (1990). A Theory of Goal Setting \& Task Performance (p. 544). Prentice Hall College Div.

Maynard, Micheline (October 22, 2002). Incentives Still Leave G.M. Short of Market Goal. New York Times. http://www.nytimes.com/2002/10/22/business/incentives-still-leave-gm-shortof-market-goal.html?sec=\&spon=\&pagewanted=all

Ordóñez, L., Schweitzer, M. E., Galinsky, A. D., \& Bazerman, M. H. (2009). Goals gone wild: How goals systematically harm individuals and organizations. Academy of Management Perspectives, 23(1), 6-16. 
Schweitzer, M. E., Ordóñez, L., \& Douma, B. (2004). Goal Setting as a Motivator of Unethical Behavior. Academy of Management Journal, 47(3), 422-432.

Staw, B. M., \& Boettger, R. D. (1990). Task revision: A neglected form of work performance. Academy of Management Journal, 33(3), 534-559.

The perils of goal-setting: Shooting at goals. (2009, March 10). The Economist. Retrieved March 23, 2009, from http://www.economist.com/business/displaystory.cfm?story_id=13256293. 